\title{
Management of Infected Charcot Neuroarthropathy due to Diabetes Mellitus with Half Pins External Fixator and Pinning: A Case Series
}

\author{
Maria Florencia Deslivia*, Claudia Santosa, Putu Teguh Aryanugraha, Sherly Desnita Savio, Ketut Kris Adi Marta, \\ I. Wayan Subawa, Putu Astawa
}

Department of Orthopaedics and Traumatology, Faculty of Medicine, Udayana University, Sanglah General Hospital, Bali, Indonesia

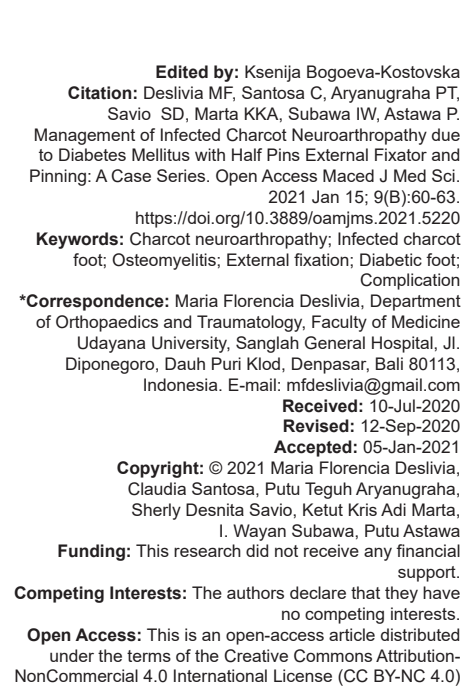

Introduction

Charcot neuroarthropathy (CN) of the foot and ankle, which is complicated with infection, is debilitating disease and presents challenges until now. Infection worsens the problem of vascularization, bone tissue reserve, and general healing process which is already severe in $\mathrm{CN}$ due to diabetes mellitus (DM) [1], [2], [3]. Therefore, the mainstay treatment is to eradicate infection with aggressive debridement of unvital tissues. Sufficient bone was then removed to allow correction of deformity to a plantigrade position. After that, the correction can be maintained using static circular external fixator [4], [5], [6].

In facilities where circular external fixators are not readily available, a number of alternatives could be reasonably utilized to treat infected Charcot foot. In our hospital, we performed staged reconstruction for these cases in which the objectives of the first surgery are to eradicate infection and provide proper condition before definitive reconstruction. Fixation of corrected foot position was performed using external fixation with half pins, or combined external fixation and pinning, or pins only depending on the severity of deformity. The purpose of this retrospective case series is to summarize the patient characteristic, type of surgical intervention, outcome, and complication of infected CN treated in our hospital.

\section{Materials and Methods}

This case series studied retrospectively patients with $\mathrm{CN}$ of the foot and ankle due to DM type II, which are complicated by infection. These patients required surgical treatment in a single institution, from 2018 until 2019. Diagnosis was based on chronic deformity (fracture or dislocation) as proven on X-ray and recently developed infection as shown through clinical, laboratory, 


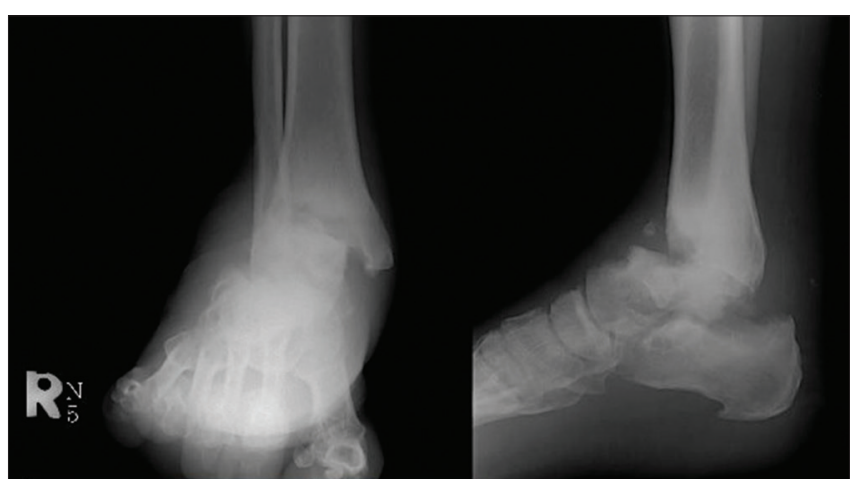

Figure 1: A 43-year-old man (Patient no. 6) was diagnosed with Charcot neuroarthropathy classified as Brodsky type 3A. Radiography of his right ankle showed destruction of tibiotalar joint

and radiological evaluation. The clinical signs include history of open wound or draining sinus.

The first step of surgery included thorough debridement of non-vital tissues, including muscle, ligament, and bone. The next step is to perform staged correction of deformity and allow plantigrade position of foot. The first step of correction is maintained with several methods including the use of half pins as external fixation and pinning. After a period of recovery, we assessed the primary outcome, which included limb salvage rate after first stage of treatment. The secondary outcome included length of stay (LOS), visual analog scale (VAS), American Orthopaedic Foot and Ankle Score (AOFAS), and complication.

The second step of correction was removal of external fixation and change into internal fixation. The prerequisites included controlled blood sugar level as shown by laboratory markers and no clinical signs of infection. After a second period of recovery, the primary and secondary outcomes were reassessed.

\section{Results}

We studied seven patients diagnosed with $\mathrm{CN}$. The mean age is 44.6 years old (range, 35-60) and mean mean body mass index was $24.08 \mathrm{~kg} / \mathrm{m}^{2}$ (range, 21.45-25.39). All patients were classified as Eichenholtz Stage $3(100 \%)$. As for the anatomic classification, some were categorized into Brodsky type $3 \mathrm{~A}$ alone $(n=3)$ (Figure 1), and type 3A with other types $(n=4)$. As for basic laboratory markers, mean pre-operative $\mathrm{Hb}$ was $9.84 \mathrm{~g} / \mathrm{dL}$ (range, 8.41-11.83), mean white blood cell count was $10.64 \times 10^{3}$ (range, $7.12 \times 10^{3}-13.87 \times 10^{3}$ ), and mean $\mathrm{HbA} 1 \mathrm{C}$ was 8.2 (range, 7-15.9). Summary of baseline characteristic is presented in Table 1.

Preoperatively, we found that $57.14 \%$ of patients had ulcer (Figure 2) and $28.57 \%$ patients had osteomyelitis based on X-ray. Signs of infection included leukocytosis $(n=6)$, soft-tissue swelling $(n=5)$, ulcer $(n=4)$, and osteomyelitis $(n=1)$ at presentation.
Table 1: Baseline characteristic of patients in the case series

\begin{tabular}{lllllllll}
\hline No & Age & Sex & $\begin{array}{l}\text { Body mass } \\
\text { index }\end{array}$ & Hb & $\begin{array}{l}\text { White blood } \\
\text { cells }\end{array}$ & HbA1C & Eichenholtz & Brodsky \\
\hline 1 & 35 & M & 25.42 & 11.83 & 8.73 & 15.9 & 3 & $3 \mathrm{~A}$ \\
2 & 37 & $\mathrm{~F}$ & 27.23 & 10.99 & 13.87 & 7.4 & 3 & $3 \mathrm{~A}, 1$ \\
3 & 43 & $\mathrm{~F}$ & 23.89 & 9.3 & 7.12 & 10.7 & 3 & $3 \mathrm{~A}, 3 \mathrm{~B}$ \\
4 & 41 & $\mathrm{~F}$ & 25.39 & 9.88 & 10.87 & 7.8 & 3 & $3 \mathrm{~A}$ \\
5 & 53 & $\mathrm{M}$ & 21.45 & 8.41 & 11.34 & 7 & 3 & $3 \mathrm{~A}$ \\
6 & 43 & $\mathrm{M}$ & 22.3 & 10.2 & 9.33 & 8.6 & 3 & $3 \mathrm{~A}$ \\
7 & 60 & $\mathrm{M}$ & 22.87 & 10.25 & 11.3 & 7.6 & 3 & $3 \mathrm{~A}, 1$ \\
\hline
\end{tabular}

Operative treatment consisted of debridement, followed by external fixation only ( $n=4)$ (Figure 3$)$, combined external fixation and pinning $(n=2)$ (Figure 4), and intramedullary pinning only $(n=1)$. The mean hospital LOS was 4.5 days (range, $3-7$ ).

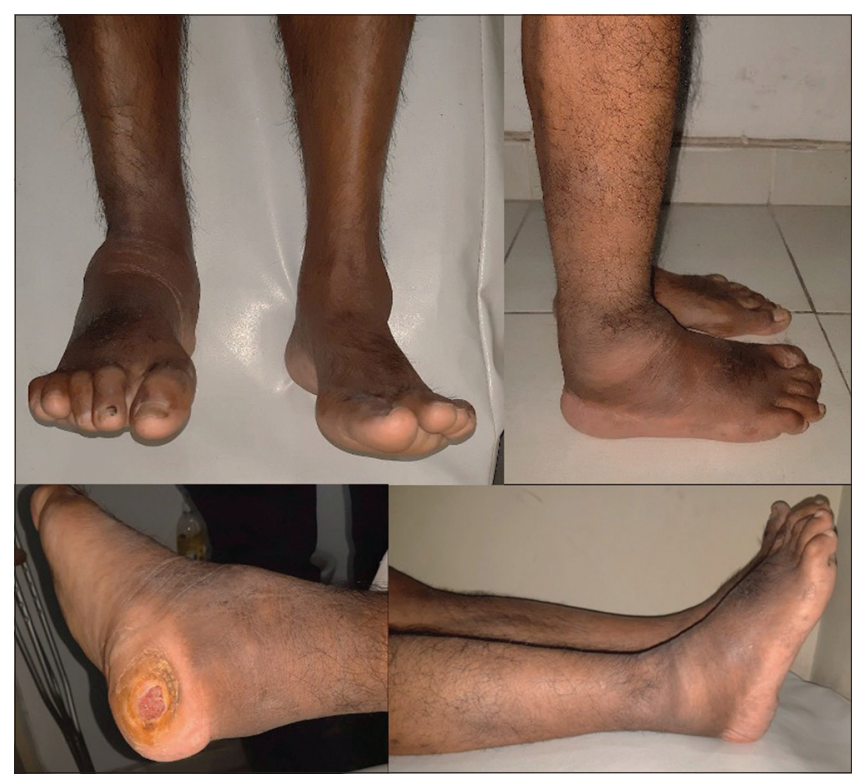

Figure 2: Pre-operative picture of Patient no. 6 showing swollen and deformed ankle, also ulcer on posterior side of heel

After a mean period of 4.56 months (range, 1.3-5.3), we performed the first assessment. Limb salvage rate was $100 \%$. One patient needed revision of external fixation due to loosening of pins on dorsum pedis by this time. We assessed the pain scale with VAS and the functional outcome through AOFAS score.

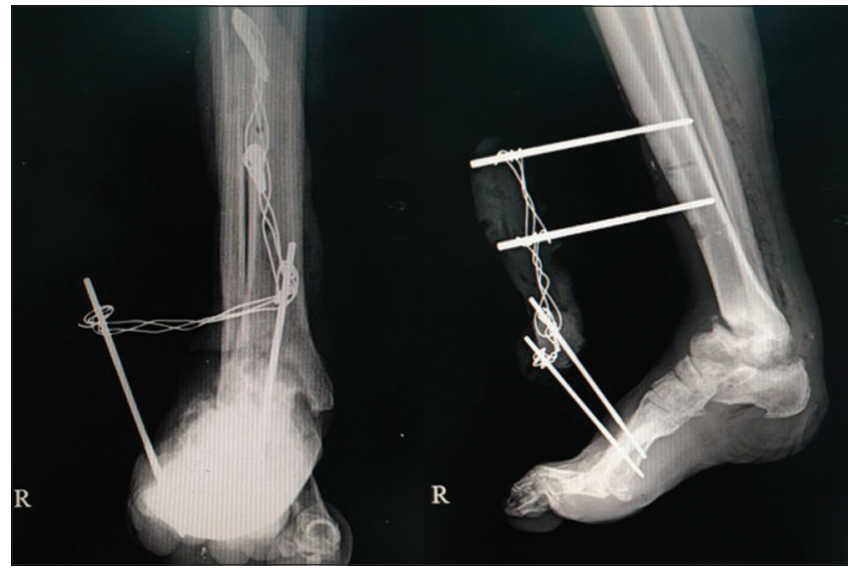

Figure 3: Patient no. 6 had external fixation with half-pins to fixate his ankle joint while waiting for the blood glucose level and infection to be under control and to continue with definitive fixation. Half-pins were implanted on his tibia and metatarsal bones, then strengthened with wires and methyl methacrylate 
Mean pre-operative VAS was 7.4 (range, 7-8) and mean post-operative VAS was 2.6 (range, 2-3). All patients experienced VAS improvement with a mean score of 4.86 (range, 4-6). Mean pre-operative AOFAS score was 22 (range, 14-35) and post-operative was 59.57 (range, 52-67), with all patients experiencing score improvement of 37.57 (range, 24-52).

As for the second assessment, the mean period was 15.02 months (range, 11.27-16.8). Limb salvage rate is still $100 \%$. Three patients had external fixation removed with one of them undergoing arthrodesis. One more patient needed external fixation revision for loosening of pins on dorsum pedis. Three other patients were lost to follow-up. Mean VAS was 0.75 (range, $0-2)$. The mean improvement of VAS compared to last follow-up was 1.75 (range, 0-3). Mean AOFAS score was 66.25 (range, 57-77), with all patients experiencing score improvement of 8.5 (range, 5-12). Ulcer wounds healed satisfactorily for all patients (Figure 5).

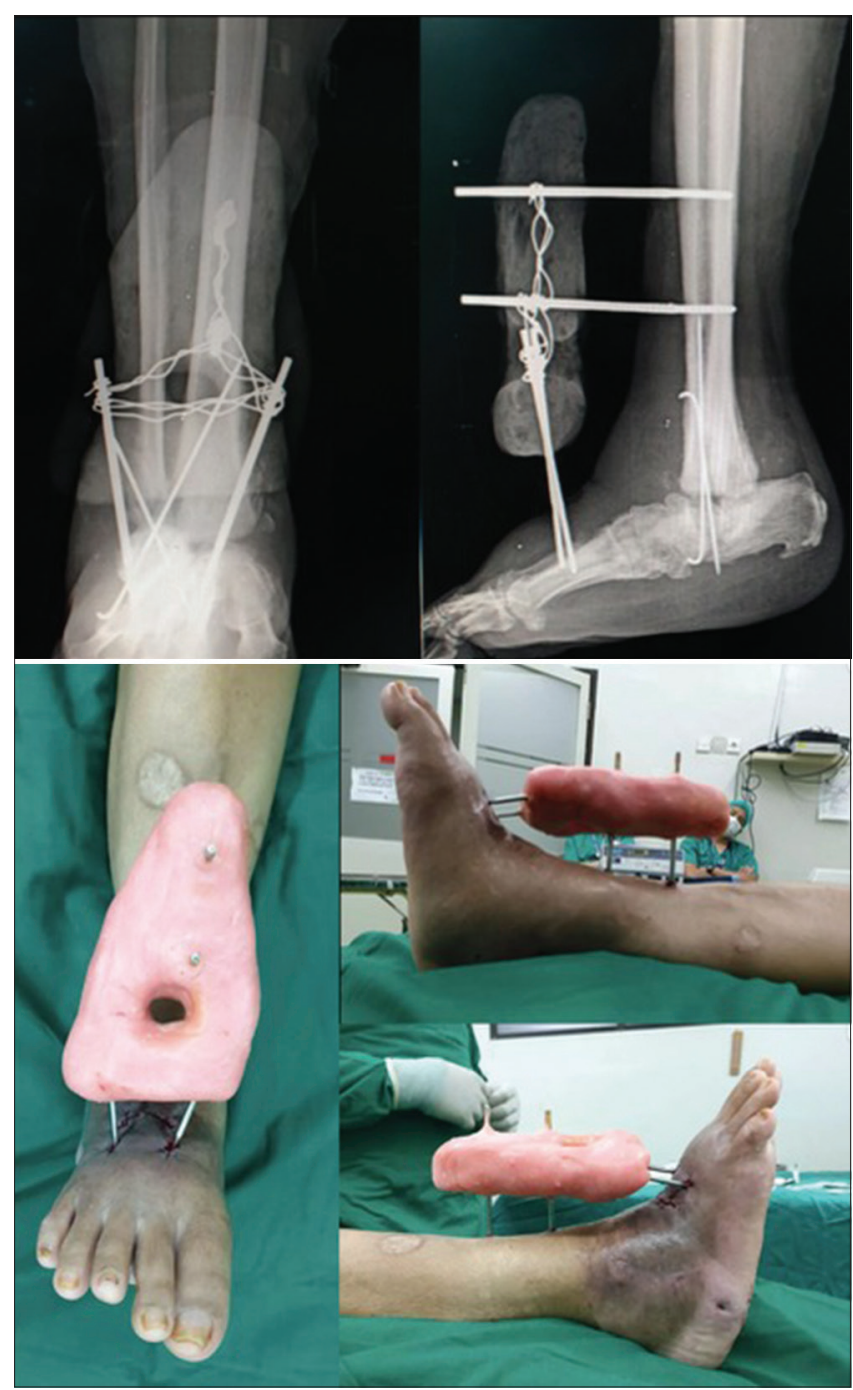

Figure 4: A 43-year-old woman (Patient no. 3) whose talus and tarsal bones were destructed due to charcot neuroarthropathy underwent debridement. Patient's ankle and foot was fixated in plantigrade position using half pins external fixation. During hospitalization period, patient's blood glucose was uncontrolled and there were clinical signs of infection, therefore a multidisciplinary approach of surgeons and endocrinologists were applied. Patient reported improvement in terms of pain and function after a period of 4 months

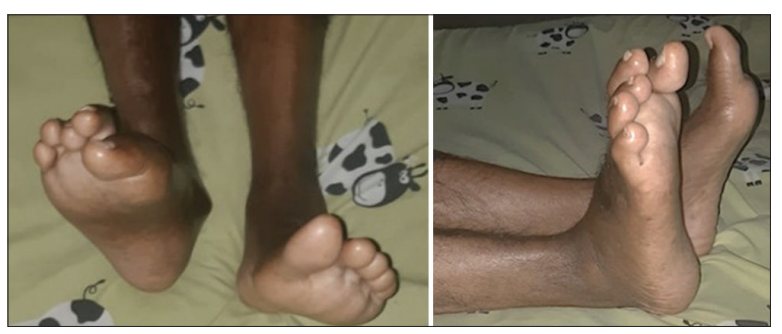

Figure 5: Patient no. 6 had external fixation removed with satisfying pain relief and hence, improvement of American Orthopaedic Foot and Ankle Score. Ulcer also healed well

In this case series, revision was performed due to loosening of external fixator pins on the foot. The revision was performed with the same technique as original procedure which has been described elsewhere [7]. We fixated the ankle joint using half-pins on tibia bone and metatarsal bones and fixated them with wire and methyl methacrylate in plantigrade position. The combined procedure (external fixator and pinning with K-wires) was performed with similar technique. The addition was fixation with pinning as seen fit intraoperatively.

The summary of outcome is presented in Table 2.

Table 2: Type of fixation on each patient and the resulting VAS and AOFAS improvement

\begin{tabular}{lllll}
\hline No & Type of fixation & LOS & $\begin{array}{l}\text { VAS pre/first follow-up/ } \\
\text { second follow-up }\end{array}$ & $\begin{array}{l}\text { AOFAS pre/first follow-up/ } \\
\text { second follow-up }\end{array}$ \\
\hline 1 & Internal fixation & 7 & $7 / 2 / N A$ & $15 / 62 / \mathrm{NA}$ \\
2 & Combined & 5 & $7 / 3 / \mathrm{NA}$ & $14 / 57 / \mathrm{NA}$ \\
3 & Combined & 6 & $8 / 2 / 2$ & $28 / 52 / 57$ \\
4 & External fixation & 6 & $8 / 3 / \mathrm{NA}$ & $15 / 67 / \mathrm{NA}$ \\
5 & External fixation & 3 & $7 / 2 / 0$ & $32 / 65 / 77$ \\
6 & External fixation & 3 & $8 / 3 / 1$ & $15 / 52 / 62$ \\
7 & External fixation & 4 & $7 / 3 / 0$ & $35 / 62 / 69$ \\
\hline
\end{tabular}

\section{Discussion}

Charcot foot is especially complex when combined with diabetes. Hyperglycemic condition in diabetic patients has been shown to increase levels of advanced glycosylation end products (AGEs). This may partially explain the association between poor diabetic control and the development of Charcot as the AGEs are able to upregulate the receptor activator of nuclear factor $\kappa \mathrm{B}$ (RANK)-RANK Ligand pathway by interacting with their receptor, the RANK receptor, especially after a fracture or repetitive trauma [8]. Therefore, a multidisciplinary approach is needed to treat infected Charcot foot [4], [8].

In our series, infection was thoroughly eradicated through the choice of antibiotics, surgical debridement, and blood glucose control through medication. American Diabetes Association and the Infectious Disease Society of North America have examined evidence regarding treatment of Charcot foot with concurrent osteomyelitis and concluded that surgical excision of infected bone combined with monitored parenteral culture-specific antibiotic therapy is recommended [4], [9]. 
As for the surgical treatment, the general consensus is that correction of deformity and placement of implants should be performed after bone infection is resolved. However, recent publication offered evidence that combination of debridement and correction of deformity in one single operation yielded satisfying result [9]. Here, we performed the procedures in single stage with external fixation only, or combined internal and external fixation, or internal fixation only (Figure 2). The choice of fixation was based on the bone condition and patient's compliance.

The half-pins external fixation with methyl methacrylate is still our main choice of provisional treatment for Charcot foot fixation due to its efficiency yet relatively low cost. Most patients have good compliance with this method. The down side is the risk of pin loosening due to the osteopenic bone which commended revision. We believe this method can be widely utilized in facilities with limited resources.

In this study, we observed satisfying clinical outcome. Mean hospital LOS was 4.5 days and after a follow-up of 15 months, the limb salvage rate was $100 \%$. One patient needed revision of external fixation due to loosening of screws on metatarsal bones. Functional outcome in both short-term and long-term was satisfactory, despite the choice of fixation. Even though there were limitations, the half-pins external fixation with methyl methacrylate can be the go-to provisional treatment for $\mathrm{CN}$ as long as there is strong commitment to control blood sugar level and to minimize or eradicate infection. This method is a useful adjunct to improve the outcome in terms of eradicating infection and maintaining optimal foot position before arthrodesis.

\section{Conclusion}

In our institution, patients seek for treatment for the $\mathrm{CN}$ foot when the chronic deformity is complicated already by infection. The surgical treatment option might include external fixation, with or without internal fixation, with the aim of stabilizing the deformed joint and preparing the bone and soft tissue for definitive treatment (arthrodesis), while optimizing patients' general condition. In this study, mostly external fixation with halfpins and methyl methacrylate was used based on the bone condition and patient's compliance. Despite of its limitation, this method is effective when it is combined with strict blood glucose level and infection control.

\section{Availability of data and material}

All data generated or analyzed during this study are included in this published article.

\section{Authors' Contributions}

MFD, CS, PTA, SDS, and KKAM collected the literatures to be involved in the study. MFD and CS performed systematic analysis the literatures. MFD and IWS worked to formulate the discussion and conclusion. MFD, IWS, and PA read and approved the final manuscript.

\section{References}

1. Goldsmith L, Barlow M, Evans PJ, Srinivas-Shankar U. Acute hot foot: Charcot neuroarthropathy or osteomyelitis? Untangling a diagnostic web. BMJ Case Rep. 2019;12(5):e228597. https:// doi.org/10.1136/bcr-2018-228597

PMid:31088814

2. Ramanujam CL, Stapleton JJ, Zgonis T. Diabetic Charcot neuroarthropathy of the foot and ankle with osteomyelitis. Clin Podiatr Med Surg. 2014;31(4):487-92. https://doi.org/10.1016/j. cpm.2013.12.001

PMid:25281510

3. Short DJ, Zgonis T. Management of osteomyelitis and bone loss in the diabetic Charcot foot and ankle. Clin Podiatr Med Surg. 2017;34(3):381-7. https://doi.org/10.1016/j.cpm.2017.02.008 PMid:28576196

4. Pinzur MS, Gil J, Belmares J. Treatment of osteomyelitis in Charcot foot with single-stage resection of infection, correction of deformity, and maintenance with ring fixation. Foot Ankle Int. 2012;33(12):1069-74. https://doi.org/10.3113/fai.2012.1069 PMid:23199855

5. Saltzman CL. Salvage of diffuse ankle osteomyelitis by single-stage resection and circumferential frame compression arthrodesis. lowa Orthop J. 2005;25:47-52.

PMid:16089072

6. El-Gafary KA, Mostafa KM, Al-Adly WY. The management of Charcot joint disease affecting the ankle and foot by arthrodesis controlled by an llizarov frame. J Bone Joint Surg Br. 2009;91(10):1322-5. https://doi. org/10.1302/0301-620x.91b10.22431

\section{PMid:19794167}

7. Hernigou P. History of external fixation for treatment of fractures. Int Orthop. 2017;41(4):845-53. https://doi.org/10.1007/ s00264-016-3324-y

PMid:27853817

8. Haslbeck KM, schleicher E, Bierhaus A, Nawroth P, Haslbeck M, Neundörfer B, et al. The AGE/RAGE/NF-(kappa)B pathway may contribute to the pathogenesis of polyneuropathy in impaired glucose tolerance (IGT). Exp Clin Endocrinol Diabetes. 2005;113(5):288-91. https://doi.org/10.1055/s-2005-865600 PMid:15926115

9. Rogers LC, Frykberg RG, Armstrong DG. The diabetic Charcot foot syndrome: A report of the joint task force on the Charcot foot by the American diabetes association and the American podiatric medical association. Diabetes Care. 2011;34:2123-9. https://doi.org/10.1007/978-1-59745-075-1_14 